\title{
Correction to: Patterns of distribution, abundance and composition of forest terrestrial orchids
}

\author{
Vladan Djordjević ${ }^{1}$ (D) Spyros Tsiftsis ${ }^{2,3} \cdot$ Dmitar Lakušić $^{1} \cdot$ Slobodan Jovanović $^{1}$ • \\ Ksenija Jakovljević ${ }^{1}$ - Vladimir Stevanović ${ }^{1,4}$
}

Published online: 27 October 2020

(C) Springer Nature B.V. 2020

\section{Correction to: Biodiversity and Conservation https://doi.org/10.1007/s10531-020-02067-6}

In the original publication of the article, there were two minor errors identified. They are as follows:

1. The value, "3.954s" in the last paragraph on page 4 under section "Data collection", should read "3.95.4s"

2. The title of Table 1 on page 7 should read as "Results of OMI (outlying mean index) analysis; Occ-occurrences..." instead of "Results of OMI (outlying mean index) analysis; Occ-ccurrences..."

The original article has been corrected.

Publisher's Note Springer Nature remains neutral with regard to jurisdictional claims in published maps and institutional affiliations.

The original article can be found online at https://doi.org/10.1007/s10531-020-02067-6.

Vladan Djordjević

vdjordjevic@bio.bg.ac.rs

1 Faculty of Biology, Institute of Botany and Botanical Garden, University of Belgrade, Takovska 43, Belgrade 11000 , Serbia

2 Department of Forest and Natural Environment Sciences, International Hellenic University, P.O. Box 172, 1st km Dramas - Mikrochoriou, Drama 66100, Greece

3 Academy of Science of the Czech Republic, Global Change Research Institute, Belidla 4a, Brno 603 00, Czech Republic

4 Serbian Academy of Sciences and Arts, Kneza Mihaila 35, Belgrade 11000, Serbia 